\title{
OS DESAFIOS DA GESTÃO DEMOCRÁTICA NAS ESCOLAS MUNICIPAIS DE EDUCAÇÃO INFANTIL DO MUNICÍPIO DE BARCARENA-PA
}

\author{
THE CHALLENGES OF DEMOCRATIC MANAGEMENT IN \\ MUNICIPAL SCHOOLS OF CHILDHOOD EDUCATION IN THE \\ CITY OF BARCARENA-PA
}

\author{
Geise Corrêa Teles ${ }^{1}$ \\ Maria Antonia Corrêa Teles ${ }^{2}$
}

\begin{abstract}
Resumo
Segundo a Lei N. 9.394/96 que fundamenta a LDB, as instituições públicas devem ser administradas com base no princípio da Gestão Democrática, que consiste num arranjo de atitudes e ações que devem propor a participação social de toda a comunidade escolar na tomada de decisões. Nesse contexto, o presente artigo objetiva analisar como os gestores mediam os conflitos do cotidiano escolar e em que medida levam em consideração os princípios da gestão democrática. Foi realizado levantamento bibliográfico e entrevistas com gestores de escolas públicas do município de Barcarena-PA. Como resultado constatou-se que a maioria dos gestores ainda não colocam em prática os postulados da Gestão Democrática.
\end{abstract}

Palavras-chave: Educação; Conflitos; Hierarquia; Gestão Democrática.

\begin{abstract}
According to Law No. 9.394 / 96 that underlies the LDB, public institutions must be managed based on the principle of Democratic Management, which consists of an arrangement of attitudes and actions that must propose the social participation of the entire school community in decision-making. In this context, the present article aims to analyze how managers mediate conflicts in school daily life and how they use the principles of democratic management. A bibliographic survey and interviews with public school managers in the municipality of Barcarena-PA were carried out. As a result, it was found that most managers still do not put into practice the postulates of Democratic Management. Keywords: Education; Conflicts; Hierarchy; Democratic management.
\end{abstract}

\section{Introdução}

Desde que foi regulamentada na década 90, a gestão democrática passou a ser um

\footnotetext{
1 Mestre em Geografia pela Universidade Federal do Pará (UFPA). Doutoranda do Programa de PósGraduação em Sustentabilidade da Universidade de São Paulo (USP). E-mail: geise-correa@usp.br 2 Graduada em Letras com habilitação em língua Portuguesa pela Universidade Federal do Pará (UFPA). Especialista em Gestão Educacional pelo Centro Universitário Leonardo Da Vinci (UNIASSELVI). antoniacteles@hotmail.com
} 


\section{REVISTA DE ADMINISTRAÇÃO EDUCACIONAL}

\section{ISSN -2359-1382}

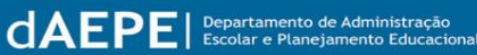

slogan para escolas e estabelecimentos de ensino, cujos princípios envolvem uma administração compartilhada. Porém, na prática, observa-se que a maioria dessas instituições, principalmente as públicas, ainda estão presas dentro de um sistema de gestão que possui estruturas hierárquicas fundamentadas em ideias tradicionais de ensinoaprendizagem, dificultando o exercício da autonomia das escolas, que é um dos princípios básicos da gestão democrática.

A gestão democrática está pautada numa visão crítico-reflexiva, que ao contrário das ideias tradicionais, vê nos conflitos uma oportunidade para o crescimento do grupo, pois compreende que eles fazem parte das relações humanas, e que a forma de administrálos é que faz a diferença para uma boa gestão. E, dentro desses princípios, diferentemente da visão conservadora, o conflito não é visto como um problema, mas como uma forma de crescimento pessoal dos sujeitos envolvidos e do coletivo (LIBÂNEO, 2013).

Sabe-se que o papel do gestor é importante para o funcionamento de uma escola e, principalmente, para o cumprimento do seu objetivo maior, que é o desenvolvimento do ensino-aprendizagem. Esse processo não é exclusivo da relação professor-aluno, passando por como a gestão trate e dê espaço para o diálogo com seus funcionários e toda a comunidade escolar. Isso quer dizer que esse gestor precisar ter certas aptidões para o exercício dessas práticas democráticas, que podem ser construídas por meio de princípios.

Tendo em vista a importância do papel do gestor na mediação de conflitos nas instituições de ensino, sua postura pode ou não promover o exercício da gestão democrática. Com base nessa afirmativa, o presente artigo objetiva analisar como os gestores mediam os conflitos no cotidiano escolar e se levam em consideração os princípios da gestão democrática. A análise foi feita com base na pesquisa qualitativa e teve por instrumento entrevistas semidirigidas com gestores de escolas públicas de educação infantil do município de Barcarena-PA.

Além dos princípios da gestão democrática destacados por Luck, et al (2002), reforça-se a importância do diálogo como uma das principais ferramentas para abertura de uma gestão compartilhada, pois a solução de conflitos abrange o interesse dos indivíduos, sem sacrificar o objetivo da comunidade escolar, uma vez que nesse processo de gestão, 


\section{REVISTA DE ADMINISTRAÇÃO EDUCACIONAL}

\section{ISSN -2359-1382}

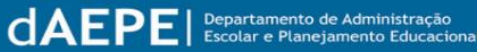

também existem regras e normas, que devem ser acordadas e cumpridas, por isso, o planejamento também se torna uma ferramenta importante.

Acreditamos que o uso dos princípios da gestão democrática são elementos necessários que prezam pela construção do indivíduo como cidadão, cujas aptidões ultrapassam o saber formal e auxiliam na construção de uma sociedade mais justa. A pesquisa nos permitiu saber sobre os avanços e lacunas que precisam ser preenchidas para o alcance de uma gestão compartilhada, que também podem ser recorrentes em outros lugares do Brasil.

\section{Materiais e Métodos}

O presente estudo caracteriza-se pelo uso de uma abordagem metodológica interdisciplinar, baseado numa pesquisa descritiva e exploratória (LAKATOS; MARCONI, 2010), com levantamento de dados secundários, ou seja, na análise de material bibliográfico de livros e artigos científicos, que abordam o tema tratado e na busca de dados primários, isto é, na construção de dados por meio de entrevistas e análises. Nesse sentido, pode-se dizer que é uma pesquisa de caráter qualitativo, pois embora investigue alguns dados numéricos, baseia-se fundamentalmente no entendimento geral de uma problemática, abrindo espaço para outras interpretações.

Como contribuição teórica, utilizamos as obras de Libâneo (2004; 2013), Luck (2002; 2010), Heredia (1998), Crispino (2007) entre outros, sendo também realizada uma pesquisa de campo, e entrevistas semidirigidas. Segundo Passos (2013), uma entrevista semidirigida corresponde a um roteiro de perguntas-chave que orientam o pesquisador a direcionar seus questionamentos, para não esquecer de indagar sobre informações cruciais para sua análise. Ela foi aplicada aos gestores de cinco escolas, localizadas em bairros periféricos de Barcarena-PA. Essas instituições foram escolhidas pela facilidade de acesso e pela disponibilidade de seus gestores, no período de coleta de dados.

As entrevistas objetivaram identificar os conflitos recorrentes no cotidiano escolar e como os gestores mediam esses impasses. Conforme presente na literatura, para análise do exercício de uma gestão democrática, avaliou-se a inclusão dos seus princípios básicos: 


\section{REVISTA DE ADMINISTRAÇÃO EDUCACIONAL}

ISSN -2359-1382

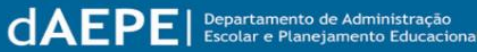

autonomia, descentralização e participação. No processo de mediação também considerou-se a valorização do diálogo e a importância do planejamento para os gestores entrevistados.

Contribuição Teórica- Gestão Democrática e Mediação de Conflitos nas Escolas.

A Lei de gestão democrática instituída na Constituição Federal de 1988, art. 206 inciso VI e a Lei de Diretrizes e Bases-LDB N. 9.394/96, em seu artigo 14, inciso II, determinaram uma nova postura a gestão das escolas públicas, baseada na maior autonomia e flexibilidade das instituições na tomada de decisões, além disso, propuseram uma gerência participativa. A partir dessas disposições, as escolas começaram a construir uma nova forma de organização, mas ainda estão longe de conseguir se dissociar das velhas formas de gestão conservadora, pautadas na setorização e monopólio de decisões, alimentados institucionalmente.

Segundo Luck, et al (2002) a construção da gestão democrática envolve alguns princípios básicos como a autonomia, descentralização e participação, que devem ser trabalhados como elementos basilares para a construção de uma administração em favor da coletividade. Contudo, conseguir alcançá-los dentro de um arranjo institucional que ainda favorece a concentração de decisões na figura do gestor, no caso das escolas, dos diretores, não é uma tarefa simples.

Diante dessa realidade, questiona-se sobre como alcançar tais princípios? A resposta perpassa pela construção de uma nova forma de organização da gestão, que envolvem mecanismos de um arranjo conjunto de administração. De acordo com Libâneo (2004), para a construção de uma gestão democrática deve-se antes de tudo, compartilhar as decisões e informações da escola com a coletividade. Porém, essa prática participativa no processo de gestão envolve planejamento, que se constrói por meio do uso de algumas ferramentas como o Projeto Político Pedagógico-PPP, o Plano de Ação da escola, entre outros, que devem considerar as particularidades sociais, políticas, econômicas e culturais de cada ambiente educacional. Assim,

As instituições e organizações sociais precisam formular objetivos, ter um plano 
de ação, meios de sua execução e critérios de avaliação da qualidade do trabalho que realizam. Sem planejamento a gestão ocorre ao sabor das circunstâncias, as ações são improvisadas, os resultados não são válidos (LIBÂNEO, 2004, p. 149).

Sem planejamento, a gestão continuará autoritária, pois não terá construído mecanismos de trabalho que possibilitem compartilhar suas decisões e, consequentemente, a comunidade escolar não será envolvida com os objetivos que essa gestão pretende alcançar. O planejamento também se mostra importante para a função social da escola, voltada para um ensino-aprendizagem que valoriza, não apenas a formação técnica, mas também a cidadania.

Outra ferramenta importante para a construção da gestão democrática é a visão que se tem sobre conflitos. Para Belmar (2005), conflito é um processo natural da sociedade, que pode ser positivo para a mudança e crescimento pessoal, mas também pode ser negativo, quando mal administrado, todavia, não se pode ignorado. Construir um processo de gestão democrática envolve enxergar os conflitos como uma forma de oportunidade para o crescimento interpessoal e da coletividade, e isso implica incluir no planejamento da escola, formas de mediação desses conflitos (LIBÂNEO, 2013).

Para construir uma gestão democrática, deve-se também mudar a forma de pensar o papel do gestor na escola e o conceito de liderança. Oliveira (2005) afirma que o gestor é o líder, mas isso não the confere poderes absolutos sobre a tomada de decisões, pelo contrário, ele deve conhecer sua equipe de trabalho e ponderar da melhor forma possível suas opiniões, para convergir com os objetivos da escola, que devem estar além dos seus julgamentos pessoais, o planejamento é fundamental nesse processo.

De acordo com Luck (2010), liderança é o processo de influenciar e mobilizar esforços orientados por uma visão clara e abrangente dos objetivos da organização, mas segundo ela, a liderança compartilhada vai além desse processo, porque envolve o exercício da cidadania e o compartilhamento das decisões, orientados por objetivos comuns, que também são construídos coletivamente. Em outras palavras, para que o gestor assuma uma liderança compartilhada, ele deve estimular os funcionários no exercício de suas competências, valorizando também suas qualidades pessoais, integrando-os no grupo por meio do investimento das relações interpessoais, como um estímulo para que 


\section{dAEPEI}

contribuam voluntariamente para os objetivos da escola.

Todavia, é importante ressaltar que no processo de gestão compartilhada também existem regras e normas, que devem ser cumpridas por todos os envolvidos. A diferença é que existe um acordo de construção dessas regras e normas, que são reguladas pelas relações de convivência, valorização pessoal e respeito as diferenças, ou seja, são organizadas de forma democrática, de que maneira que fique claro, os direitos e obrigações de cada um, tudo em prol do objetivo maior da escola.

Quer dizer que a autoridade exercida na gestão democrática não deve ser confundida com autoritarismo da gestão tradicional, pois a primeira é legitimada pela motivação e respeito mútuo em busca de objetivos comuns, e a última é pautada na imposição e na inflexibilidade, que impedem o crescimento pessoal dos indivíduos (MARANESI; ALMEIDA, 2017).

Assim, no exercício da gestão democrática, o gestor reconhece o valor de cada membro da sua equipe, individual e coletivamente, permitindo identificar pontos positivos e negativos do grupo. Esse tipo de vivência possibilita a problematização dos conflitos existentes no seu ambiente de trabalho, pois preza-se pela cooperação e colaboração em que cada um saiba reconhecer o seu espaço e o do outro, ou seja, enxergam-se os conflitos como uma oportunidade de crescimento do coletivo e com isso surgem formas de mediálos.

A mediação, por sua vez, pode ser entendida como uma assistência em que um indivíduo imparcial, no caso o mediador, analisa as questões em que as partes discordam, na presença de ambas, com o objetivo de desenvolver opções, considerar alternativas e chegar a um acordo que seja mutuamente aceitável (HEREDIA, 1998). É, na verdade, um processo de reorientação das relações sociais, que busca de forma madura resolver as diferenças pessoais ou grupais.

Existem atualmente vários autores que discutem a importância da mediação no contexto da gestão de instituições, como as escolas. Heredia (1998), por exemplo, fala sobre a relevância que os programas de mediação de conflitos possuem para uma boa gestão, uma vez que esse processo inclui reflexão, diálogo, análise e avaliação. Levando os 


\section{REVISTA DE ADMINISTRAÇÃO EDUCACIONAL}

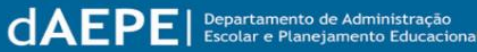

indivíduos a ponderarem suas atitudes e trabalharem sua inteligência emocional.

Para Sales (2010), a mediação possui quatro objetivos: a boa administração dos conflitos; a prevenção dos seus efeitos danosos; a inclusão social; e, o exercício da resolução pacífica das divergências no ambiente escolar. Todos esses objetivos envolvem um trabalho de autoconhecimento e amadurecimento pessoal, que não estão no currículo dos gestores, tão pouco há espaço para a composição dessas relações nas agendas anuais, porém se faz necessário a construção delas, para fortalecer a relação de confiança do grupo.

O gestor precisa de algumas aptidões essenciais para resolver conflitos, entre elas estão: a disponibilidade, a tolerância, a flexibilidade, a coragem, a serenidade, o respeito, a responsabilidade e a cooperação (QUERA, 2005). O problema é que nem sempre os gestores se dedicam a construção dessas habilidades, pois estão presos a uma estrutura de gestão que pouco valoriza o desenvolvimento pessoal e interpessoal. E, sem a valorização dessas relações dificilmente haverá nas escolas a implantação de programas de mediação que apresentem resultados eficientes.

Entendemos que o primeiro passo para construção de um bom programa de mediação é admitir a presença de conflitos e identificar seus gatilhos iniciais. Crispino (2007) faz inúmeras classificações de conflitos nas escolas, porém afirma que não há receita na mediação deles que possa ser aplicada indistintamente a escolas diferentes, pois cada escola é uma rede complexa de relações e de valores e, por tal, merece um diagnóstico específico, um modelo próprio. Contudo, há alguns itens que permitirão definir o tipo de programa que se deve implantar. Para seu diagnóstico, segundo esse autor, devese responder algumas perguntas: Qual o caráter da mediação? Quem são os atores envolvidos? Qual seu nível de abrangência? etc.

Assim, pode-se dizer que, a mediação de conflitos e os princípios da gestão democrática prezam pela construção do indivíduo como cidadão, cujas aptidões ultrapassam o saber formal, e auxiliam na construção de uma sociedade mais justa. Mas vale lembrar que seu exercício perpassa pela construção de um planejamento, que prevê formas de mediação coerentes com a realidade de cada escola. 


\section{REVISTA DE ADMINISTRAÇÃO EDUCACIONAL}

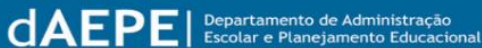

\section{Resultados e Discussões- Principais Conflitos Existentes nas Escolas e as Soluções Encontradas pelos Gestores.}

O município de Barcarena localiza-se no Nordeste do estado do Pará, a aproximadamente $114 \mathrm{~km}$ da capital Belém, e possui uma população de aproximadamente 100 mil habitantes segundo dados do IBGE (2010). A maioria das crianças e jovens da cidade dependem das 173 escolas públicas municipais do lugar, das quais, 13 são escolas de educação infantil, ou seja, escolas que matriculam crianças de 04 a 05 anos.

Dessas 13 escolas foram escolhidas 5 (quatro localizadas em bairros periféricos e uma localizada no bairro central da cidade). Elas possuem uma média de 297 alunos, sendo que a escola que possui menos alunos matriculados, tem o menor número de funcionários e a que possui o maior número de alunos, também tem o maior número de servidores. No quadro abaixo, pode-se verificar as principais características dessas escolas, que por sigilo, solicitado por seus gestores não terão seus nomes divulgados.

Quadro 1- Informações sobre as escolas analisadas em campo.

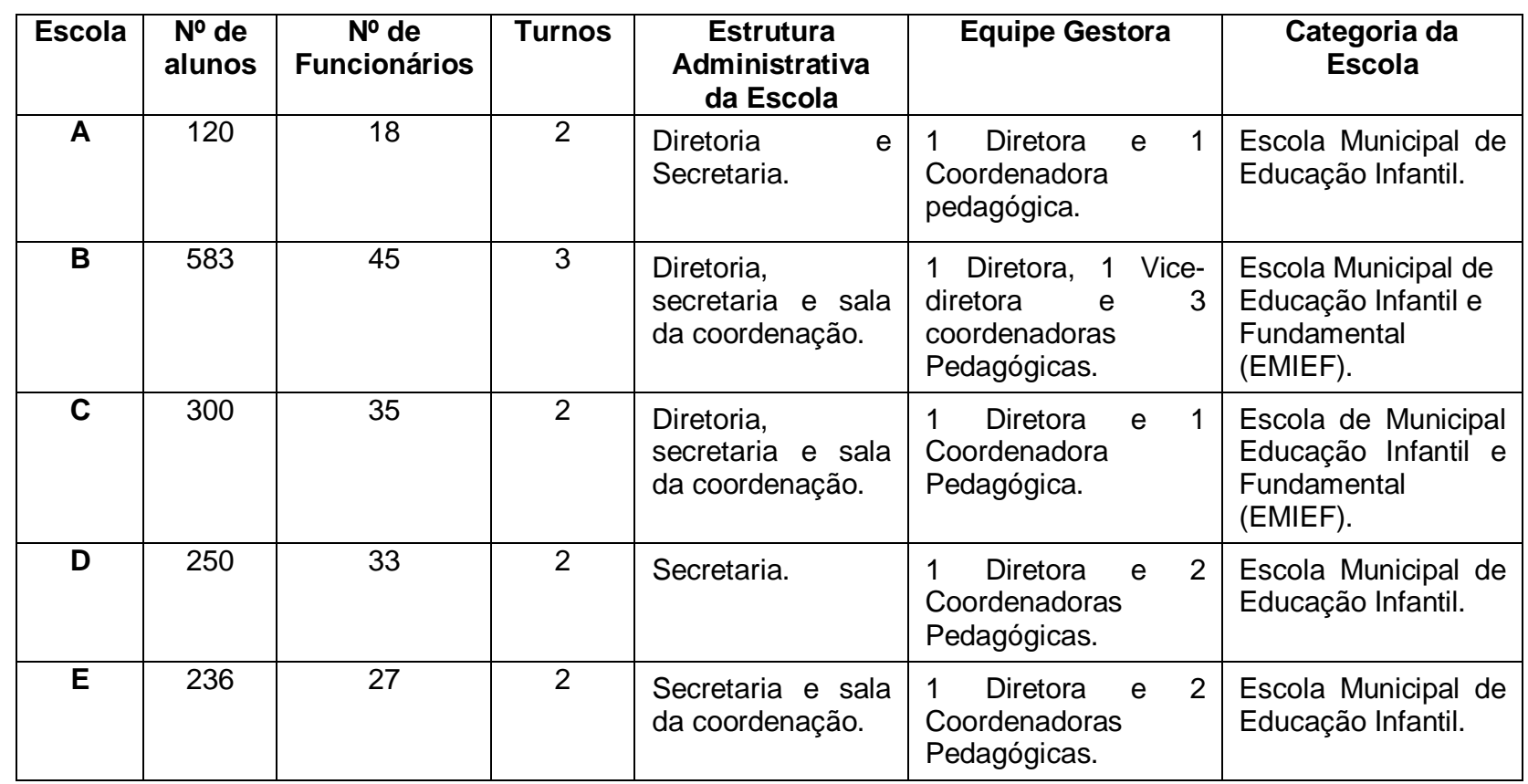

Fonte: Organizado pelas autoras, 2019.

No quadro acima, pode-se notar que, das cinco escolas visitadas, duas atendem 


\section{REVISTA DE ADMINISTRAÇÃO EDUCACIONAL}

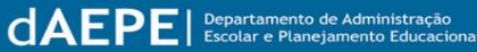

além da educação infantil, o ensino fundamental I, por isso, elas possuem um número mais expressivo de alunos e consequentemente, um número maior de funcionários. Observa-se também que elas possuem uma equipe gestora bem reduzida e algumas trabalham num espaço administrativo compactado.

Como principais conflitos identificados pelos gestores entrevistados, destacam-se: O descumprimento de função, falta de empatia, dificuldade no trato das relações interpessoais como intolerância e inflexibilidade, constante difusão de boatos e fofocas, dificuldade de alguns funcionários em entender seu papel no grupo, incompreensão da ideia de coletividade e sentimento de pertencimento.

Para tentar mediar tais conflitos, a gestora da escola A diz usar o diálogo como ferramenta principal e tenta repassar a sua equipe a necessidade de cada um assumir o compromisso com o seu trabalho, e enfatiza também o respeito como elemento principal para uma vivência harmônica. Para ela, ser uma boa gestora significa acima de tudo ser humana, ter humildade, simplicidade e saber dialogar sem rodeios.

A gestora da escola B também usa o diálogo como principal ferramenta na intervenção de conflitos "rotineiramente usa-se a conversa como instrumento de esclarecimento da função de cada um e de sua responsabilidade para com o coletivo". Ela relatou também que seu principal embasamento teórico é o regime jurídico educaciaonal e unificado do município, e que em casos de não encontra uma solução para o conflito, busca apoio junto à Secretaria de Educação, pois ela enxerga essa esfera como uma mediadora adequada para solucionar certos antagonismos. Para essa diretora, ter uma boa gestão significa comunicar-se, ou seja, "ter uma ligação eficiente entre os funcionários, para que contribuam com o coletivo e sigam objetivos comuns".

Para resolver os conflitos cotidianos, a gestora da escola $\mathrm{C}$ usa a mediação como mecanismo de resolução de empasses. Foi relatado por essa diretora, que ela mesma atua como mediadora dos conflitos e procura ouvir constantemente os funcionários para que todos atuem nas decisões da escola, evitando que dessa forma ampliem-se as divergências. Segundo essa entrevistada, ser uma boa gestora significa ser conhecedora de leis, do fazer pedagógico e da sua própria equipe de trabalho, valorizando o respeito ao exercício de sua 


\section{dAEPEI}

função, o diálogo e o espaço do outro.

Segundo a gestora da escola D, o diálogo é a principal ferramenta para resolver impasses no ambiente escolar, por isso ela também atua como mediadora do conflito, procurando entender os motivos que levam os funcionários a divergirem, buscando uma solução pacífica, que possa favorecer os objetivos da coletividade. Para ela, ser uma boa gestora é entender cada um dos seus funcionários individualmente, seus anseios, motivações, qualidades e defeitos, pois somente dessa forma é possível perceber de que forma cada um pode contribuir para o grupo.

O principal mecanismo usado pela gestora da escola E também é o diálogo, orientado por uma mediação instantânea entre as partes, para que não se acumulem divergências. A gestora afirmou que as conversas sempre reforçam o papel e o valor de cada um, individual e coletivamente, isso serve de incentivo para que eles sejam mediadores, ou reguladores de conflitos e não fiscalizadores, ou seja, pensem mais nos objetivos da escola. Para ela ser uma boa gestora significa demonstrar liderança, sabedoria, parceria, conhecer a realidade da escola, manter-se atualizado dos conhecimentos da escola, ter interesse na comunidade escolar e principalmente pensar sempre no coletivo.

Observa-se que gestoras entrevistadas enfrentam conflitos muitos similares, quase todos desencadeados pela dificuldade nas relações interpessoais do grupo. Todas apresentam uma visão coerente entre o que é ser um bom gestor, e como mediam seus conflitos cotidianos. Seus argumentos evidenciam que possuem aptidões importantes para o exercício de uma boa gestão conforme colocado por Quera (2005), que perpassam por um equilíbrio de entender que os conflitos devem ser mediados para o bem da coletividade, e que os demais funcionários da escola também devem ter essas aptidões estimuladas, como parte dos objetivos da boa convivência no ambiente escolar.

Outra questão importante a ser pontuada é a interação em rede na relação de conflitos, colocada por apenas uma gestora. Essa interação é fundamental e demanda um planejamento, conforme argumentado por Libâneo (2013). Quando bem executada, ela permite que a gestão entenda a magnitude dos conflitos e se cabe ou não, ele ser resolvido somente no âmbito interno da escola. Por isso, é basilar se ter um programa de mediação 


\section{dAEPE|}

conflitos como propõe Crispino (2007).

Todas as gestoras falaram sobre o diálogo como um importante instrumento na resolução de conflitos e duas argumentaram diretamente sobre a mediação, porém, não foi comentado sobre a existência de programas ou bases de suporte a mediação dos empasses. O que significa dizer que, possivelmente, que não há um planejamento em rede e nem no âmbito interno da escola que dê suporte à mediação de conflitos. E, a inexistência de programas de mediação no planejamento das escolas pode fazer com que as gestoras recorram a diálogos sem efeito, que apenas acumulem ou adiem conflitos.

Em relação aos princípios básicos que norteiam a gestão democrática: autonomia, descentralização e participação (Luck, et al, 2002), as entrevistadas questionaram a autonomia da escola e da própria figura do gestor na tomada de decisões. A maioria afirmou que as decisões do planejamento estão centralizadas na Secretaria de Educação, impossibilitando até mesmo que algumas medidas internas a escola sejam tomadas. Com isso, entendemos que a privação da autonomia do gestor descaracteriza um planejamento inerente as particularidades da escola e consequentemente as necessidades e desenvolvimento de seus funcionários.

A imposição de algumas decisões pode refletir negativamente na organização interna da escola, pois os funcionários são apenas comunicados e não consultados, o que consequentemente, gera uma imagem do gestor como autoritário e centralizador de decisões, afastando a comunidade escolar dos debates de interesse coletivo. Quando há esse distanciamento a mediação de conflitos torna-se cada vez mais difusa.

A forma como as gestoras entrevistadas intervêm nos conflitos, assim como a sua visão sobre o que é ser um bom gestor, evidenciam que elas possuem um olhar críticoreflexivo sobre a organização político-administrativa da escola, porém, não possuem instrumentos suficientes para construírem uma gestão participativa, e, consequentemente, usar o intermédio de conflitos para gerar a transformação das relações interpessoais e crescimento do coletivo.

O plano de ação das escolas não prevê reuniões para trabalhar situações conflituosas, mesmo que tenham sido recorrentes nos anos anteriores. Em cada escola 


\section{REVISTA DE ADMINISTRAÇÃO EDUCACIONAL}

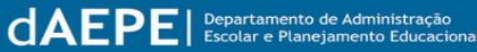

pesquisada, são feitas apenas duas reuniões gerais por semestre. As demais reuniões, como por exemplo, as de segmento, só são realizadas de acordo com a necessidade. As reuniões para intervir em conflitos são feitas informalmente.

O diálogo pode ser potencializado na intervenção de conflitos pelo planejamento da mediação, que conduz a gestão a agir de forma adequada em cada situação. Como foi comentado por Crispino (2007), não existe uma receita universal para atender a todas as escolas, mas existem fios condutores de ação baseados na reunião de informações sobre as particularidades de cada instituição, que podem ser agregadas e organizadas para contribuírem no processo de mediação de conflitos.

Em outras palavras, faz-se necessário o uso da mediação como ferramenta para a resolução de conflitos nas escolas, porém é necessário que os gestores entendam como se constrói uma mediação eficiente, que vai além de uma simples conversa. Para isso é imprescindível que se construa dentro dos instrumentos de gestão pedagógica como o PPP, e o Plano de Ação, espaços de discussão e ocorra uma reformulação na forma de pensar e mediar conflitos por toda a rede de ensino, o que vai além do próprio município.

\section{Considerações Finais}

A gestão democrática exerce papel fundamental na ampliação da democracia participativa, pois ela valoriza não só o exercício do saber formal, mas também o desenvolvimento integral do ser humano. Vale destacar que ela se dissocia da gestão tradicional, por enxergar a ideia de conflito como uma oportunidade de crescimento pessoal e interpessoal para o grupo.

A análise das entrevistas realizadas com os cinco gestores das escolas de educação infantil do município de Barcarena permitiu entender que essas instituições se encontram numa estrutura de ensino que privilegia a centralização das decisões, oferece pouca autonomia para escolas, em relação a Secretaria de Educação e apresentam formas de mediar conflitos sem planejamento prévio.

Entre os principais conflitos destacados pelas gestoras entrevistadas estão os desencadeados pelas relações interpessoais conflituosas, cujo planejamento da escola não 


\section{REVISTA DE ADMINISTRAÇÃO EDUCACIONAL}

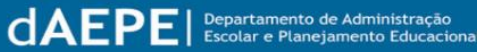

prevê ações diretas para amenizá-los. O diálogo aparece, na fala de todas as entrevistas, como a principal ferramenta usada para solucionar esses empasses, contudo, nem todos os utilizam de forma eficaz e orientada, em muitos casos há conversas sem efeitos visíveis.

Por isso, propõem-se aqui que a mediação orientada pelo planejamento deva ser prevista no PPP, Plano de Ação e demais instrumentos pedagógicos da escola. Os gestores podem construir seu plano de mediação, a partir dos princípios da gestão democrática, descentralizando as decisões, de forma a permitir maior participação do coletivo, deixando claro os direitos e deveres de cada um. Para isso, é importante que as normas que regulamentam o comportamento dos funcionários sejam construídas por todos e que sejam cumpridas indistintamente. Todavia, como já foi enfatizado, esse processo requer planejamento e trabalho individual para amadurecimento pessoal, não só do gestor, mas de todos os funcionários. Abrindo espaço para reflexão, diálogo, análise e avaliação, levando os indivíduos a ponderarem suas atitudes e trabalharem sua inteligência emocional.

Diante do exposto, fica evidente a necessidade de se pensar na mediação para ponderar conflitos nas escolas e na construção desses planos de intervenção, que devem ser guiados e orientados pelos princípios da gestão democrática, tais como, a autonomia, descentralização e participação.

\section{Referências}

BELMAR, A. M. O Jogo de Papéis: Recurso Metodológico para a Resolução de Conflitos Escolares. IN_: VINYAMATA, E. (Org.). Aprender a partir do Conflito: Conflitologia e Educação. Porto Alegre. Artmed, 2005.

BRASIL. A Lei de Gestão Democrática Instituída na Constituição Federal de 1998, art. 206 inciso VI. Disponível em: < https://www.jusbrasil.com.br/topicos/10650329/inciso-vido-artigo-206-da-constituicao-federal-de-1988>. (último acesso 26/07/2019).

BRASIL. Lei de Diretrizes e Bases da Educação Nacional. Lei $n^{0}$ 9.394, de 20 de dezembro de 1996. Estabelece as Diretrizes e Bases da Educação Nacional. Disponível em: <http://www.planalto.gov.br/ccivil_03/leis/19394.htm>. (último acesso 26/07/2019).

CHRISPINO, Álvaro. Gestão do conflito escolar: da classificação dos conflitos aos modelos de mediação. Ensaio: aval. pol. públ. Educ., Rio de Janeiro, v. 15, n. 54, p. 11-28, 2007. 


\section{dAEPEI}

HEREDIA, R. A. S. Resolución de Conflictos en la Escuela. Ensayos y Experiencias. Buenos Aires, ano 4, n. 24, p. 44-65, jul./ago. 1998.

Instituto Brasileiro de Geografia e Estatística (IBGE)- Censo Demográfico 2010. Disponível em: < https://cidades.ibge.gov.br/brasil/pa/barcarena/panorama> (último acesso 26/07/2019).

jul./set. 2004.

LIBÂNEO, J. C. Organização e gestão da escola: teoria e prática. $6^{\text {a }}$ ed. rev. e ampl. São Paulo: Heccus Editora, 2013.

LIBÂNEO, J.C. Organização e Gestão da Escola: Teoria e Prática, 5. ed. Goiânia, Alternativa, 2004.

LÜCK, Heloísa, et al. A Escola Participativa: O Trabalho do Gestor Escolar. 6 ed. Rio de Janeiro: DP\&A, 2002.

LÜCK, Heloísa. A explicitação do significado de liderança. In: LÜCK, Heloísa. Liderança em gestão escolar. Série: Cadernos de Gestão. Petrópolis: Vozes, 2010.

MARANESI, Tânia; ALMEIDA, Laurinda Ramalho de. Gestão Escolar: O Diretor Concepções e Sentimentos que se Entrecruzam. XIII Congresso Nacional de Educação. Curitiba $\quad-\quad$ PR, 2017. 2 Disponível em: <educere.bruc.com.br/arquivo/pdf2017/25978_12859.pdf> (último acesso 25/07/2019).

MARCONI, M. A.; LAKATOS, E. M. Fundamentos de Metodologia Científica. 7.ed. São Paulo: Atlas, 2010.

OLIVEIRA, M. A. M. (org.) Gestão Educacional: Novos Olhares Novas abordagens. Petrópolis, RJ: Vozes, 2005.

PASSOS, M.M. Paisagem e meio ambiente (Noroeste do Paraná). $1^{\text {a }}$ Edição. Maringá: Eduem, 2013.

QUERA, P. O Conflito: Escutar, Aprender e Criar. IN_: VINYAMATA, E. (Org.). Aprender a partir do Conflito: Conflitologia e Educação. Porto Alegre. Artmed, 2005.

SALES, Lília Maia de Moraes. Mediare: Um Guia Prático para Mediadores. 3 ed. rev. Fortaleza: Universidade Federal do Ceará, 2010. 